\title{
Dynamic profile of EVs in porcine oviductal fluid during the periovulatory period
}

\author{
Inga Laezer ${ }^{1}$, Sergio E Palma-Vera, Fan Liu², Marcus Frank ${ }^{3,4}$, Nares Trakooljul ${ }^{5}$, \\ Andreas Vernunft ${ }^{1}$, Jennifer Schoen ${ }^{1}$ and Shuai Chen ${ }^{1}$ \\ ${ }^{1}$ Institute of Reproductive Biology, Leibniz Institute for Farm Animal Biology (FBN), Dummerstorf, Germany, \\ ${ }^{2}$ Department of Chemical Biology, Leibniz-Forschungsinstitut für Molekulare Pharmakologie (FMP), Berlin, Germany, \\ ${ }^{3}$ Medical Biology and Electron Microscopy Centre, Rostock University Medical Center, Rostock, Germany, \\ ${ }^{4}$ Department Life, Light \& Matter, University of Rostock, Rostock, Germany and ${ }^{5}$ Institute of Genome Biology, \\ Leibniz Institute for Farm Animal Biology (FBN), Dummerstorf, Germany
}

Correspondence should be addressed to S Chen: chen@fbn-dummerstorf.de or to / Schoen: schoen.jennifer@fbn-dummerstorf.de

\begin{abstract}
In mammals, around the time of ovulation, the hormonal profile dynamically changes in synchrony with reproductive events occurring in the oviduct, that is, sperm arrival, fertilization, and early embryo development. Extracellular vesicles (EVs) have been recently recognized as key components of the embryonic milieu; however, composition and function of oviductal EVs during this crucial period remains to be further explored. Therefore, we initially characterized EVs from porcine oviductal fluid specifically around the critical ovulation window: that is, estrus (E), late estrus (LE, day of expected ovulation), post ovulation (PO), and additionally diestrus (D). Total EV numbers gradually rose from D to E, LE and $P O(P<0.05)$, which corresponded to the total EV protein amount $(P<\mathbf{0 . 0 5})$. Strikingly, the mean size of EVs in PO was significantly smaller than in $E$ and LE groups, which also had a lesser proportion of small EVs $(P<\mathbf{0 . 0 5})$. The EV protein cargoes during the periovulatory period were further analyzed by mass spectrometry. Qualitative analysis detected 1118 common proteins, which are most enriched in the cellular component of EVs/ exosomes. Hierarchical clustering indicated similar protein profile within the biological replicates, but large discrepancy among stages. Further quantitative analysis discovered 34 and 4 differentially expressed proteins in the comparison between E and PO and in the comparison between E and LE, respectively. The dynamic EV protein profile together with the quick adaption in EV size and quantity suggests that porcine oviductal EV secretion are under the hormonal influence during the estrus cycle.

Reproduction (2020) 159 371-382
\end{abstract}

\section{Introduction}

Oviductal fluid (OF) is generated by transudation of molecules from serum and stromal cells as well as by molecules secreted by the epithelial cells lining the oviductal lumen (Leese 1988). This dynamic milieu plays a key role for final maturation of oocytes and spermatozoa, fertilization, and early embryonic development (Coy et al. 2012, Maillo et al. 2016). The amount of OF as well as its composition is regulated by steroid hormones which alter the secretory activity of epithelial cells as well as the permeability of the epithelium and oviductal capillaries during the estrous cycle (Georgiou et al. 2005, Li and Winuthayanon 2017). According to Carrasco et al., the highest amount of OF in sows is synthesized in late follicular phase, when ovulation occurs, and decreases in the following cycle stages (Carrasco et al. 2008). The same pattern can be found in the total protein amount per oviduct (Carrasco et al. 2008). Further '-omics' analyses have revealed that the profile of metabolites, steroid hormones, and proteins in the oviductal fluid of cows and ewes fluctuates according to the cycle stage (Lamy et al. 2016a,b, 2018, Soleilhavoup et al. 2016).

Recently, EVs have been identified as key components of the OF in human, mice, and cattle (Al-Dossary et al. 2013, Alminana et al. 2017, Bathala et al. 2018). Originally considered as 'cell waste' in the transferrin pathway (Harding etal. 1983), EVs are now known for their multiple functional roles in cell-to-cell communication under both physiological and pathological conditions (Edgar 2016). Most recent papers mention two different EV types, which differ in size range, composition, and formation: exosomes and microvesicles (MVs) (Edgar 2016, van Niel et al. 2018). Exosomes are nanoparticles of endosomal origin with a size range between 40 and $100 \mathrm{~nm}$, whereas MVs have a diameter between 100 and $1000 \mathrm{~nm}$ and are directly shed from the plasma membrane (Lee et al. 2012, Edgar 2016, van Niel et al. 2018). In the following, both exosomes and MVs 
are referred to as EVs, as commonly used separation methods do not allow precise discrimination between them (Thery et al. 2018). Due to their ability to transfer functional macromolecules, for example, RNA species and proteins, oviductal EVs have lately been proposed as new messengers in embryo-maternal communication (Pavani et al. 2016). Indeed, EVs derived from bovine OF as well as from conditioned medium of bovine oviductal epithelia cells have demonstrated positive influence on embryonic development in vitro (Lopera-Vasquez et al. 2016, 2017, Alminana et al. 2017).

The porcine estrous cycle lasts on average for over 21 days. In estrus (approx. cycle day 20-21) and early metestrus (aprox. cycle day 1-2), gametes arrive in the oviduct and fertilization as well as early embryonic development occurs. Hence, the periovulatory phase is more relevant for gamete/embryo-maternal interaction. The sows' hormonal profile dramatically changes within this short period: estrogen level peaks during estrus, followed by the luteinizing hormone (LH) peak around $11 \mathrm{~h}$ later, which initiates ovulation for approximately 36-42 h (Brussow et al. 2009). After ovulation, the level of progesterone quickly rises within the first 2 days (Henricks et al. 1972). As recent transcriptome studies in different species reported that global gene expression of the oviduct epithelium was regulated by steroid hormones (Cerny et al. 2015, Acuna et al. 2017, Chen et al. 2018), we hypothesize that the different cycle stages, which are featured by dynamic hormonal levels, exert substantial effects on oviductal EVs.

A recent publication on bovine oviductal EVs has presented the first evidence for varying EV cargoes among different cycle stages (Alminana et al. 2018). In this study, authors focus on analyzing pools of OFs which were obtained within a time interval of several days pre- or post- ovulation, respectively.

Here, we aim to closely examine the porcine oviductal EV population around the period of ovulation, that is, in estrus (E), late estrus (LE, expected ovulation day), and post ovulation (PO), by using OF from individual animals. As comparison, we included samples collected in diestrus (D). EVs were characterized on the basis of EV markers, morphology, size, and distribution profile; moreover, the EV protein cargo was determined by global proteomic analysis.

\section{Materials and methods}

\section{Sample collection}

For this study, pure bred German Landrace sows from the FBN pig breeding facilities with similar physical condition (age: $16 \pm 3$ months; body weight: $206 \pm 28 \mathrm{~kg}$; mean \pm S.D.) were sampled. The animals were used for meat production and underwent no experimental treatment, diagnostic sampling, or any other intervention before killing. Animal handling as well as the killing was in accordance with applicable laws, relevant guidelines, and provisions for ethical regulations. Based on the knowledge that sows come synchronized into estrus after weaning, sows were slaughtered at certain days after weaning and used for collecting oviducts at different cycle stages. Due to the natural occurring variations of the onset of estrus and the time of ovulation after weaning, the available samples were assessed by an additional approach to gain more precise classification of cycle stages. Oviducts were assigned to the cycle stage groups by a combination of clinical estimated criteria of the sows before slaughter according to Soede and Kemp (1997) and morphological criteria of the ovaries postmortem according to Carrasco et al. (2008). An overview of the including and excluding criteria for the group assembly are shown in Table 1. The cycle stages of collected oviducts were classified as estrus (E), late estrus (LE), post ovulation (PO), and diestrus (D). For oviducts in estrus (E), sows were slaughtered on day 4 after weaning, if they showed onset of estrus within the day before and a positive standing reflex. The corresponding ovaries both had to carry more than ten follicles with diameters of $8-11 \mathrm{~mm}$. Late estrus (LE) oviducts were collected from sows slaughtered 5 days after weaning that showed onset of estrus 2 days before. Both ovaries had to exhibit more than ten follicles close to ovulation $(>11 \mathrm{~mm})$. As this day is considered as the day of peak of ovulation (Soede \& Kemp 1997), several animals (about $20 \%$ ) were excluded from the study due to completed ovulation and presence of corpora hemorrhagica. Oviducts from sows slaughtered 7 days after weaning (3-4 days after onset of estrus, 2 days after expected ovulation) were assigned to the post ovulation group (PO), if both ovaries exhibited about ten early corpora lutea. Animals with a late onset of estrus, non-ovulated follicles or recently developed corpora hemorrhagica were

Table 1 Classification of cycle stages for collected samples according to a combination of clinical examination of the sows before slaughter and morphological observation of the ovaries post mortem.

\begin{tabular}{|c|c|c|c|c|}
\hline \multirow[b]{2}{*}{ Group } & \multirow{2}{*}{$\begin{array}{l}\text { Day after } \\
\text { weaning }\end{array}$} & \multirow[b]{2}{*}{ Animal criteria } & \multicolumn{2}{|c|}{ Ovarian criteria } \\
\hline & & & Inclusion & Exclusion \\
\hline Estrus & 4 & $\begin{array}{l}1 \text { day after onset of estrus; } \\
\text { Positive standing reflex }\end{array}$ & $\begin{array}{l}>10 \text { follicles with diameters between } \\
8 \text { and } 11 \mathrm{~mm} \text { on both ovaries }\end{array}$ & $\begin{array}{l}\text { Only small follicles, ovaries } \\
\text { without functional bodies }\end{array}$ \\
\hline $\begin{array}{l}\text { Late estrus (expected } \\
\text { ovulation day) }\end{array}$ & 5 & $\begin{array}{l}2 \text { days after onset of estrus; } \\
\text { positive standing reflex }\end{array}$ & $\begin{array}{l}>10 \text { follicles }(>11 \mathrm{~mm}) \text { close to } \\
\text { ovulate on both ovaries }\end{array}$ & $\begin{array}{l}\text { Completed ovulations, corpora } \\
\text { hemorrhagica }\end{array}$ \\
\hline $\begin{array}{l}\text { Post ovulation } \\
\text { (metestrus) }\end{array}$ & 7 & $3-4$ days after onset of estrus & $\begin{array}{l}\text { About } 10 \text { early corpora lutea on both } \\
\text { ovaries }\end{array}$ & $\begin{array}{l}\text { Non-ovulated follicles or recently } \\
\text { developed corpora hemorrhagica }\end{array}$ \\
\hline Diestrus & 19 & $\begin{array}{l}16-15 \text { days after standing } \\
\text { heat ( } 13-14 \text { days after } \\
\text { expected ovulation) }\end{array}$ & $\begin{array}{l}\text { Several fully developed, surface } \\
\text { vascularized, orange-yellow corpora } \\
\text { lutea on both ovaries }\end{array}$ & $\begin{array}{l}\text { Non-ovulated follicles, ovaries } \\
\text { without functional bodies }\end{array}$ \\
\hline
\end{tabular}

Including and excluding criteria are listed below. 
excluded. Diestrus (D) oviducts were taken from sows slaughtered 19 days after weaning (i.e. 15-16 days after standing heat, 13-14 days after expected ovulation), if both ovaries carried several fully developed, surface vascularized, orange-yellow corpora lutea. Finally, oviducts from four sows/stage were selected for this investigation and further processed. Samples were transported on ice within $20 \mathrm{~min}$ to the lab and freed from surrounding tissue. Oviduct tubes were washed in filtered PBS Dulbecco (Biochrom L1825). To obtain the oviductal fluid, each tube was slowly rinsed with $8 \mathrm{~mL}$ filtered PBS Dulbecco. The gained fluid from both tubes per animal was pooled and centrifuged at $300 \mathrm{~g}, 4^{\circ} \mathrm{C}$ for $10 \mathrm{~min}$, and supernatants were transferred to a fresh tube and centrifuged at $2000 \mathrm{~g}, 4^{\circ} \mathrm{C}$ for $30 \mathrm{~min}$ (Sigma 3K15). Supernatants were stored at $-70^{\circ} \mathrm{C}$ until use.

\section{EV separation}

We adapted the protocol described by Rider et al. (2016) with minor modifications. During preparation, samples were always centrifuged at $4{ }^{\circ} \mathrm{C}$ and kept cold under sterile conditions. Briefly, after thawing, oviduct flushing samples $(8 \mathrm{~mL})$ were mixed 1:1 with 16\% polyethylene glycol (PEG Mn 6000, Sigma 81260) in sodium chloride (1 M; Carl Roth 3957.1). After incubation overnight at $4^{\circ} \mathrm{C}$ the samples were centrifuged at $3214 \mathrm{~g}$ for $1 \mathrm{~h}$ (Sigma 3K15). The pellet was re-suspended in $1 \mathrm{~mL}$ sterile filtered PBS Dulbecco. The suspension was split into two parts, transferred to $10 \mathrm{~mL}$ ultracentrifugation tubes (sealing cap: 03613; tube: 03929 Thermo Fisher), filled up to $10 \mathrm{~mL}$ with sterile filtered PBS Dulbecco and centrifuged at $100,000 \mathbf{g}$, for $70 \mathrm{~min}$ (Ultracentrifuge Sorvall Discovery 90SE, Fixed Angle Titanium T890 Rotor, 11690, k factor 127, Thermo Fisher). Finally samples were either re-suspended to $250 \mu \mathrm{L}$ in filtered PBS Dulbecco or to $200 \mu \mathrm{L}$ in Exosome Resuspension Buffer (Total Exosome RNA \& Protein Isolation Kit, Thermo Fisher 4478545) by shaking for $30 \mathrm{~min}$. Proteinase inhibitors (Sigma P8340-1ML) were added to samples diluted in Resuspension Buffer. All samples were stored in aliquots at $-70^{\circ} \mathrm{C}$ for later use.

\section{Transmission electron microscopy (TEM)}

TEM investigations were performed according to the standard protocol descripted by Thery et al. (2006). Due to the higher density of EVs in E, LE, and PO stages, these samples were diluted $30 \times$ times compared to the D stage. EVs were visualized in TEM Zeiss EM902 operated at an acceleration voltage of $80 \mathrm{kV}$. Digital images were acquired using a sidemounted $1 \times 2 \mathrm{k}$ frame transfer CCD camera (Proscan, TRS Scheuring) using iTEM camera control and image processing software (Olympus Soft Imaging Solutions).

\section{Nanoparticle tracking analysis (NTA)}

To determine the concentration and particle size of EVs, NTA ( $n=4$ animals/stage) was executed by Cell Guidance Systems using the Zetaview instrument (Particle Metrix) equipped with $488 \mathrm{~nm}$ laser and $0.703 \mu \mathrm{m} / \mathrm{px}$ camera. EV samples were diluted in filtered PBS Dulbecco to achieve an appropriate particle concentration range $\left(10^{6}\right.$ to $10^{10}$ particles per $\left.\mathrm{mL}\right)$. For each sample, measurement was performed for 11 positions with two cycles of reading using the software ZetaView 8.03.08.02. The temperature was automatically sensed during each measurement. Analysis parameters were set as: maximum size $1000 \mathrm{~nm}$, minimum size $10 \mathrm{~nm}$, and minimum brightness of 20 .

\section{RNA/protein extraction, bioanalyzer and BCA assay}

The EV RNA/protein content was isolated using the Total Exosome RNA \& Protein Isolation Kit (Thermo Fisher 4478545) and the amount of protein in EVs was measured using the Micro BCA Protein Assay Kit (Thermo Fisher 23235) following the manufacturers' instructions.

\section{Western blot}

Information on antibodies and corresponding dilution factors is given in Table 2. EV proteins were separated by SDS-PAGE and blotted on polyvinylidene fluoride membranes (Hartenstein TPV4). Non-specific binding sites were blocked with either 0.5\% (HSP90, OVGP1, ATP2B2, Cytochrome c) or 5\% (ESR1, CD109 and TSG101) non-fat dry milk (Carl Roth T145.3), diluted in Tris-buffered saline solution with $1 \%$ Tween 20 (TBS-T) for $1 \mathrm{~h}$ at room temperature (RT). Primary antibodies were diluted in 5\% BSA in TBS-T and incubated overnight at $4^{\circ} \mathrm{C}$. Secondary antibodies were diluted in blocking solution and incubated for $1.5 \mathrm{~h}$ at RT. The signals were detected by chemiluminescence (ECLprime, GE Healthcare) according to the manufacturer's instructions.

Table 2 Information on antibodies used for protein detection after Western blot.

\begin{tabular}{lll}
\hline Antigen & Primary antibody & Secondary antibody \\
\hline HSP90 & Rabbit anti-human & HRP-linked goat \\
& HSP90 & anti-rabbit IgG \\
Source & Cell Signaling 4874 & Cell signaling 7074 \\
Dilution & $1: 1000$ & $1: 3000$ \\
OVGP1 & Goat anti-human & HRP-linked donkey \\
& OVGP1 & anti-goat IgG \\
Source & Santa Cruz sc-46432 & Santa Cruz sc-2020 \\
Dilution & $1: 1000$ & $1: 3000$ \\
ESR1 & Mouse anti-bovine & HRP-linked goat \\
& ESR1 & anti-mouse IgG \\
Source & Santa Cruz sc-787 & Cell signaling 7076 \\
Dilution & $1: 800$ & $1: 3000$ \\
CD109 & Mouse anti-human & HRP-linked goat \\
& CD109 & anti-mouse IgG \\
Source & Santa Cruz Sc-271085 & Cell signaling 7076 \\
Dilution & $1: 1000$ & $1: 10000$ \\
TSG101 & Rabbit anti human & HRP-linked goat \\
& TSG101 & anti-rabbit IgG \\
Source & Sigma Aldrich & Cell signaling 7074 \\
& PLA0283 & \\
Dilution & $1: 5000$ & $1: 15000$ \\
ATP2B2 & Rabbit anti human & HRP-linked goat \\
& ATP2B2 & anti-rabbit IgG \\
Source & Invitrogen PA1-915 & Cell signaling 7074 \\
Dilution & $1: 1000$ & $1: 3000$ \\
Cytochrome c & Rabbit anti human & HRP-linked goat \\
& Cytochrome c & anti-rabbit lgG \\
Source & Cell signaling 11940 & Cell signaling 7074 \\
Dilution & $1: 1000$ & $1: 3000$ \\
\hline & & \\
\hline & &
\end{tabular}




\section{Mass spectrometry (MS)}

Only EV samples gained around the time point of ovulation (E, LE, PO) were analyzed by mass spectrometry, as this is the period when most crucial reproductive evens occur. Liquid chromatography mass spectrometry (LC-MS/MS) was conducted as reported previously (Chen et al. 2017). Aliquots of protein samples were thawed on ice, and $10 \mu \mathrm{g}$ protein/sample were analyzed using established SP3 digestion protocol (Hughes et al. 2019). In brief, proteins were denatured with 4\% SDS in $50 \mathrm{mM}$ $\mathrm{TEAB}$ buffer, reduced with $5 \mathrm{mM} \mathrm{DTT}$ at $56^{\circ} \mathrm{C}$ for $30 \mathrm{~min}$ and alkylated with $40 \mathrm{mM}$ chloroacetamide at RT for $30 \mathrm{~min}$ in the dark. Protein digestion was carried out using a mixture of LysC and trypsin at an enzyme-to-protein ratio of $1: 5(\mathrm{w} / \mathrm{w})$ at $37^{\circ} \mathrm{C}$ overnight. LC/MS analysis was performed using an UltiMate 3000 RSLC nano LC system coupled on-line to an Orbitrap Fusion mass spectrometer (Thermo Fisher). Reversed-phase separation was performed using a $50 \mathrm{~cm}$ analytical column (in-house packed with Poroshell 120 EC-C18, $2.7 \mu \mathrm{m}$, Agilent Technologies).

\section{Statistical analysis}

Analysis of MS data

The proteomic data were processed using the R (www.rproject.org/) Bioconductor (Huber et al. 2015) software. For qualitative analysis, a protein is considered present in one group when it was detected by at least two unique peptides for $\geq 3$ out of 4 samples. A protein is considered as unique if it was detected by at least two unique peptides in $\geq 3$ samples out of one group, but was undetectable ( $<2$ unique peptides) in at least one other group.

Differential protein expression analysis was performed based on the label-free protein abundances (LFQ intensities) using the R Bioconductor package 'Differential Enrichment analysis of Proteomics data' (DEP) (Zhang et al. 2018). Unfortunately, one protein sample had to be removed from the quantitative proteome analysis as protein measurement was found to be flawed. Therefore data of four samples were used in the LE and POgroup, while data of three samples were usable in the E group. Briefly, proteins measured in all samples of at least one group were retained and expression was normalized by performing variance stabilizing transformation using the package 'vsn' (Huber et al. 2002) through DEP's function 'normalize_vsn'. Missing data was imputed by random sampling of a left-shifted Gaussian distribution with mean corresponding to a sample's 0.01 quantile value and a S.D. equal to the median of the S.D. of all proteins for which at least $50 \%$ of samples had values (DEP's function 'impute' using the package 'imputeLCMD' (https://CRAN.R-project.org/package=imputeLCMD). Testing for differential expression between two groups was conducted with Bioconductor's 'limma' (Ritchie et al. 2015) through DEP's 'test_diff' function. Statistical significance was achieved if the adjusted $P$ value (q-value) was less or equal than 0.1 .

Data handling was done with the packages 'dplyr' (https:// CRAN.R-project.org/package=dplyr), 'stringr' (https:// CRAN.R-project.org/package=stringr) and 'reshape2' (Wickham 2007). Visualizations were done using DEP's functions 'plot_PCA', 'plot_cor' and 'plot_heatmap' as well as 'ggplot2' (Wickham 2009).

\section{Functional enrichment analysis}

As presently the pig genome is not fully annotated, we converted the identified protein symbols to the corresponding human protein Uniprot accession numbers using the Protein Analysis Through Evolutionary Relationships (PANTHER) tool and the NCBI protein database, for subsequent functional annotation. The lists of proteins were imported into the Database for Annotation and Integrated Discovery (DAVID 6.8) for gene ontology (GO) analysis (Huang da et al. 2009). Human genome was chosen as background dataset, while GO-Fat annotation sets were used in DAVID. Overrepresented biological process and cellular component GO terms with a false discovery rate (FDR) $<10 \%$ (internally estimated by DAVID) were considered as significant.

\section{Statistics}

The IBM SPSS Statistics 22 was used to analyze data from the NPT and BCA assays. The normality of data distribution was assessed by Shapiro-Wilk test. For normal distributed values one-way ANOVA followed by Fisher least significant difference (LSD) post hoc test was performed, otherwise the Mood median test was used with a $\mathrm{Cl}$ of $95 \%$.

\section{Results}

In this study, analysis of EVs have been performed according to the 'Minimal information for studies of extracellular vesicles 2018 (MISEV)' guidance released by the International Society for Extracellular Vesicles (Thery et al. 2018).

\section{Characterization of EVs derived from porcine oviductal fluid}

We characterized the isolated EVs using TEM and Western blot. Electron microscopic images showed the typical cup-shape or intact spherical morphology of EVs in all stages (Fig. 1). Due to the low quantity of EVs in D stage, no dilution was performed (Fig. 1A). A higher proportion of large vesicles in E (Fig. 1B) and LE (Fig. 1C) can be observed in comparison to PO stage (Fig. 1D). Western blot revealed bands of the expected size for the EV marker proteins CD109, heat shock $90 \mathrm{kDa}$ protein (HSP90) and tumor susceptibility 101 (TSG101) in the EV samples (Fig. 1E). HSP90 and the ESCRT-I complex subunit TSG101 were present in EVs as well as in the oviductal tissue (control), while surface marker CD109 was specifically enriched in EVs in comparison to the tissue. The mitochondria protein Cytochrome $\mathrm{c}$ and nucleus protein ESR1 functioned as purity controls, and a clear signal was exclusively detected in the oviductal tissue (Fig. 1E).

All relevant data about EV separation and characterization have been submitted to the EV-TRACK knowledge base (EV-TRACK ID: EV190005, EV Metric 78\%). 

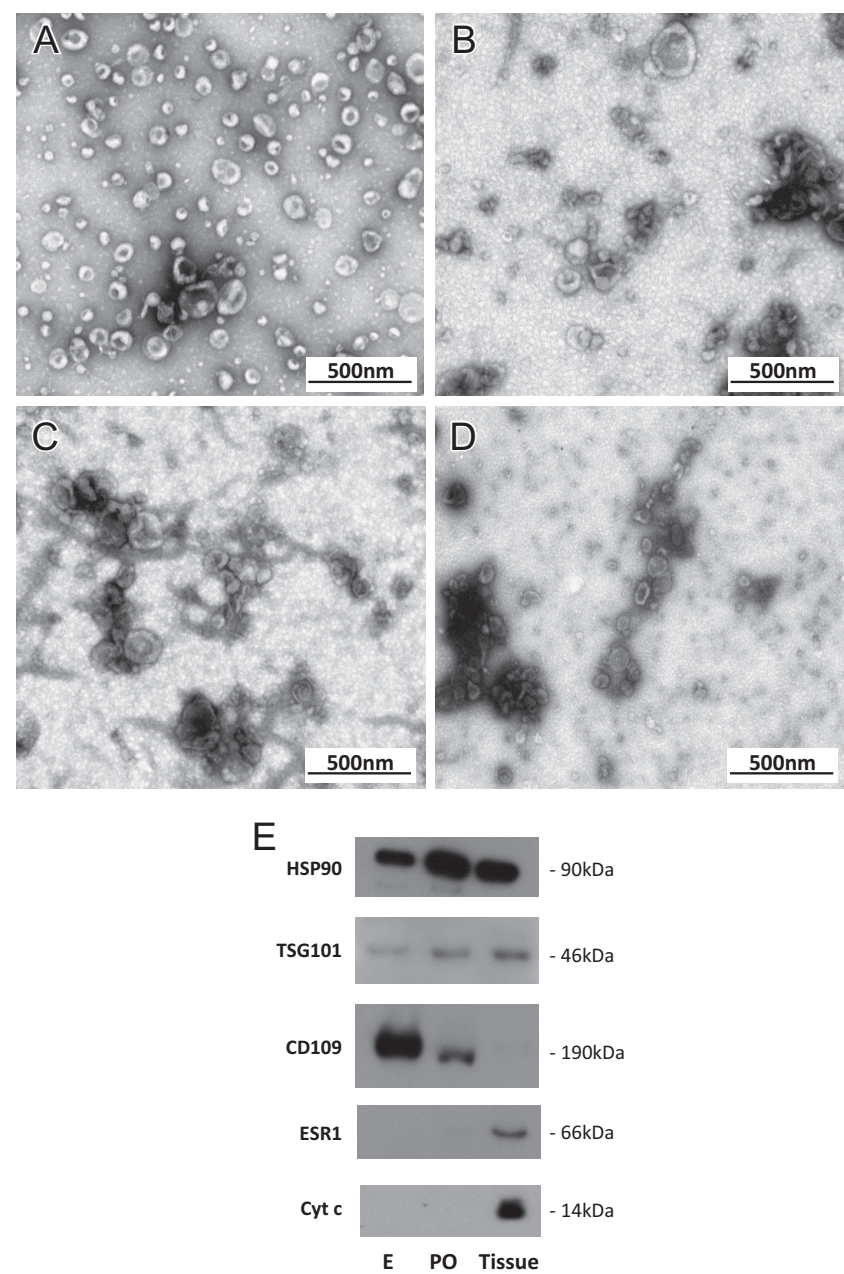

Figure 1 General characterization of separated EVs from porcine oviductal fluid after ultracentrifugation. (A, B, C and D) Transmission electron microscopic (TEM) images of EVs in diestrus (A), estrus (B), late estrus $(C)$, and post ovulation (D) stages. Samples in E, LE and PO stages (B, C and D) were diluted 30x times in comparison to D stage (A). (E) Representative western blot of known EV markers (HSP90, TSG101 and CD109), as well as nuclear estrogen receptor ESR1 and Cytochrome c (Cyt c, negative controls) in oviductal tissue and EVs. $\mathrm{D}$, diestrus; E, estrus; LE, late estrus; PO, post ovulation.

\section{Cyclic changes on the porcine oviductal EV population}

To unveil variation in EV population throughout the cycle, especially around the ovulation period, NTA and BCA measurements were performed. Generally, cycle stage demonstrated significant effects on the number and size of EVs $(P<0.05)$. The total number of particles gradually increased from $\mathrm{D}$ to $\mathrm{PO}$, with significantly more $\mathrm{EVs}$ found in $\mathrm{PO}\left(1.79 \times 10^{11} / \mathrm{sample}\right)$ than in LE $\left(5.22 \times 10^{10} /\right.$ sample), E $\left(5.59 \times 10^{10} /\right.$ sample $)$ and D $\left(4.28 \times 10^{9} /\right.$ sample; Fig. $\left.2 \mathrm{~A}, \quad P<0.05\right)$. The protein concentration of isolated samples, shown in Fig. 2B, followed a similar distribution pattern (D: $22.74 \mu \mathrm{g} / \mathrm{mL}$; E: $528.60 \mu \mathrm{g} / \mathrm{mL}$; LE: $909.79 \mu \mathrm{g} / \mathrm{mL}$; PO: $947.10 \mu \mathrm{g} / \mathrm{mL}$; $P<0.05)$. The mean and median particle sizes were determined by NTA as well. Interestingly, EVs in the PO group showed the minimum size (mean $102.35 \pm 2.30$ $\mathrm{nm}$; median $94.88 \pm 2.95 \mathrm{~nm}$ ) and were significantly smaller than $\mathrm{EVs}$ in both $\mathrm{E}$ (mean $127.73 \pm 17.21 \mathrm{~nm}$; median 119.02 $\pm 15.28 \mathrm{~nm}$ ) and LE groups (mean $137.80 \pm 7.00 \mathrm{~nm}$; median $131.43 \pm 6.25 \mathrm{~nm}$ ) (Fig. 2C, $P<0.05)$. Further data analysis confirmed a larger proportion of small EVs $($ size $<100 \mathrm{~nm})$ in $\mathrm{PO}$ than $\mathrm{E}$ and LE groups (Fig. 2D, $P<0.05$ ).

\section{Differential protein profiling of oviductal EVs around the time of ovulation}

\section{Qualitative analysis}

Comparative proteomic analysis was performed in the three stages around ovulation. The presence of proteins among groups was initially evaluated by qualitative analysis. We found 1118 proteins commonly present in all three groups (Fig. 3 and Supplementary file 1, see section on supplementary materials given at the end of this article). The most enriched clusters after functional annotation clustering of these proteins were related to EVs/exosomes, vesicle coating, transport and localization, cell adhesion and junction, small molecule binding, immune response, morphogenesis of polarized epithelium, cilium morphogenesis, cell motility, and response to peptide hormone (Supplementary file 2).

The list of group-specific proteins (Fig. 3) was further processed for gene ontology (GO) analysis by DAVID. Analysis of the list for the PO group, revealed 16 overrepresented biological process (BP) terms (Fig. 4), which were related to vesicle transport function,
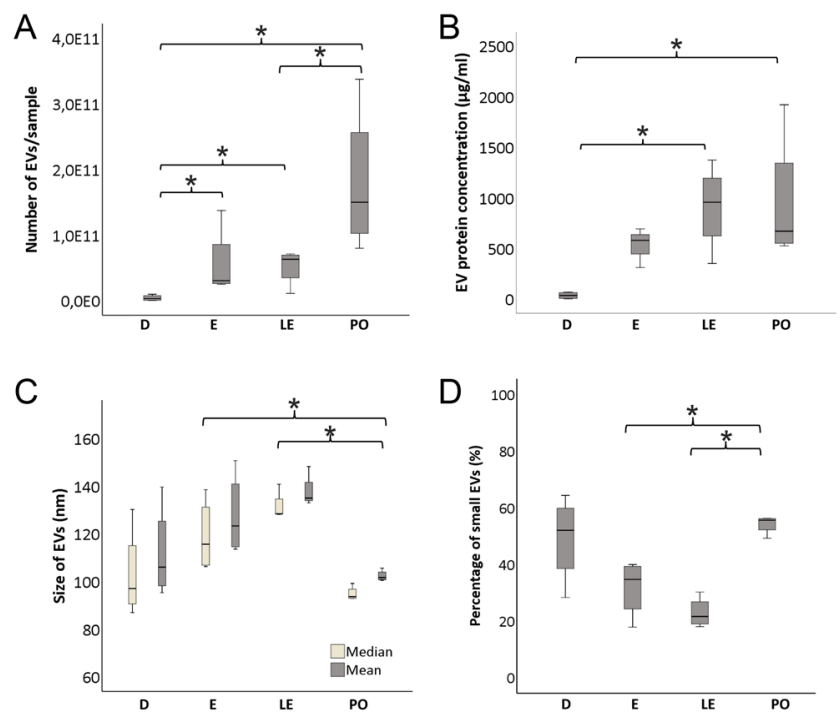

Figure 2 Quantification of the particle number (A), protein content (B), median/mean size of EVs (C), and percentage of small EVs (D) by BCA protein assay and nanoparticle tracking analysis (NTA), respectively. Small EVs are defined as particles with size smaller than 100 nm. D, diestrus; E, estrus; LE, late estrus; PO, post ovulation. Significance is indicated as $* P<0.05$. 
cellular localization and cell migration, with cellular component (CC) terms mainly relating to vesicles and Golgi compartments (Fig. 5). The enriched BP terms for the LE group were primarily associated with embryo development and macromolecule localization, while the CC terms point toward EVs and exosomes (Figs 4 and 5). Overrepresented BP terms of pre-ovulation (E) reflected functions responsible for microtubule-based events, transport, as well as blood vessel development (Fig. 4). Correspondingly, the enriched CC terms included microtubule and microtubule cytoskeleton (Fig. 5).

We further trimmed the data to identify 'unique' proteins, which were completely absent in all samples of at least one group, and discovered Kinesin-like protein (KIF15) and cartilage matrix protein (MATN1) in $\mathrm{E}$; inter alia, cortactin (CTTN) and plasminogen activator, urokinase (PLAU) in PO; pyruvate kinase M1/2 (PKM), acyl-CoA synthetase long-chain family member 4 (ACSL4) and olfactomedin 3 (OLFM3), Aquaporin 5 (AQP5), syndecan 2 (SDC2) and others were present in both $\mathrm{E}$ and LE groups, but absent in PO. The full list of unique proteins is displayed in Supplementary file 3.

\section{Quantitative analysis}

Next, we examined the relation of samples using three biological replicates in E stage and four biological replicates in LE and PO stages based on the label-free protein abundances (LFQ intensities, Supplementary file 4). The principal component analysis of the top 500 variable proteins revealed a separated profile for the groups (Fig. 6A). Then a quantitative comparison was performed using the LFQ intensities. We detected 34 DEPs (3 were double-matched to the peptides of two different species) between $\mathrm{E}$ and PO stages, and 4 DEPs in the comparison between E and LE stages (Fig. 6B and Supplementary file 5). No differential proteins were

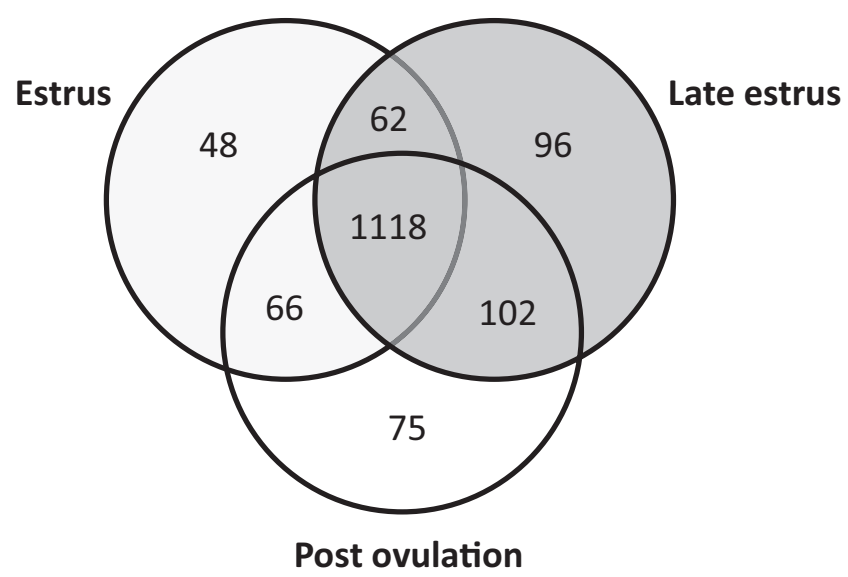

Figure 3 Visualization of the number and relation of expressed proteins among groups after qualitative analysis. Proteins identified by the presence of at least 2 unique peptides in $\geq 3$ of the 4 samples were used to produce this Venn diagram.

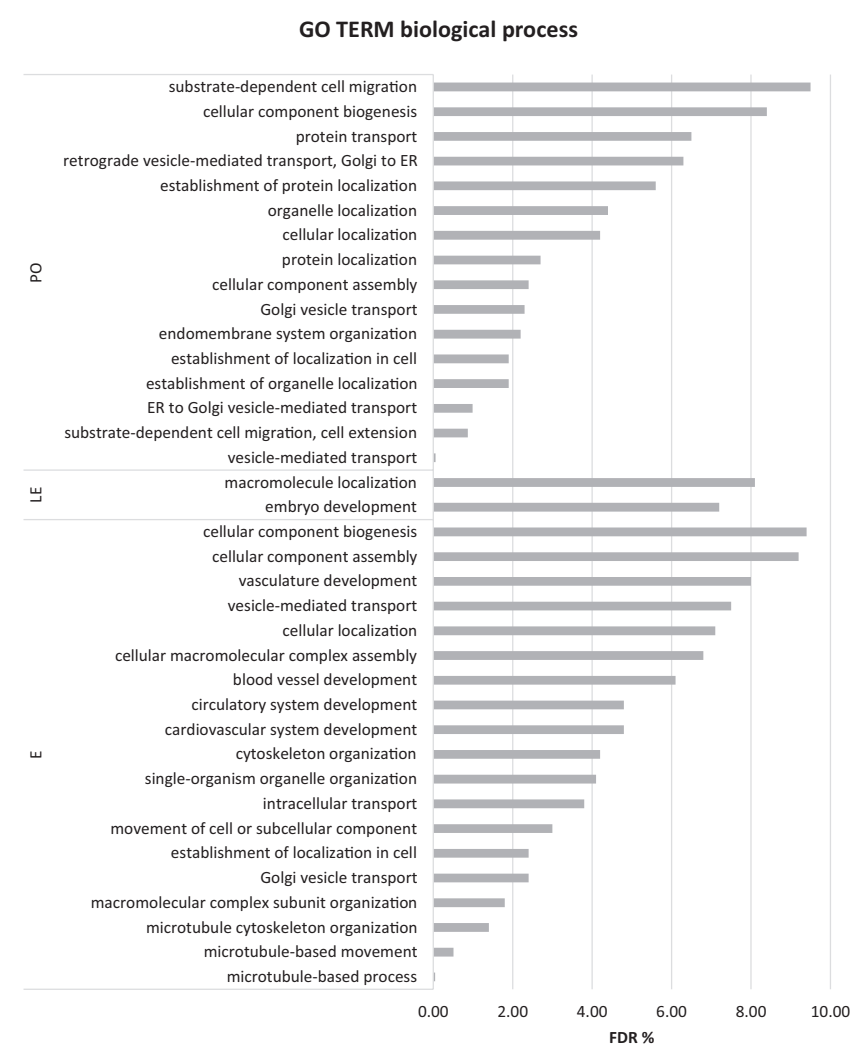

Figure 4 Enriched GO biological process terms of unique proteins in the E, LE and PO groups, respectively, after analysis by DAVID $(F D R<0.1)$. E, estrus; LE, late estrus; PO, post ovulation.

detected between LE and PO. The heatmap using all DEPs illustrated a clearly segregation based on the cycle stages, with E close to LE stage, and most distant from PO stage (Fig. 7B). Pearson correlation demonstrated that samples from the same stage were closely correlated to each other (correlation value 0.8-1.0, Supplementary file 6), and similar clustering by the group. Functional annotation showed that overrepresented BP terms for the DEPs were involved in cellular component assembly/ biogenesis, cell adhesion and wound healing, and the CC terms highlighted their location in extracellular region, extracellular exosomes/vesicles (Fig. 7).

Western blot analysis of ATP2B2 confirmed the differential abundance across all three stages around ovulation as detected by mass spectrometry (Fig. 8A). Oviduct specific glycoprotein (OVGP1 or MUC9), the main secreted protein in the oviductal fluid, showed high glycosylation at approx. $100 \mathrm{KDa}$ and $>200 \mathrm{kD}$ in the EV samples (Fig. 8B).

\section{Discussion}

In this study, we initially separated EVs from the porcine OF and performed an in-depth examination around the time of ovulation, a period when key reproductive events occur inside the oviduct. We were able to demonstrate 


\section{GO TERM cellular component}

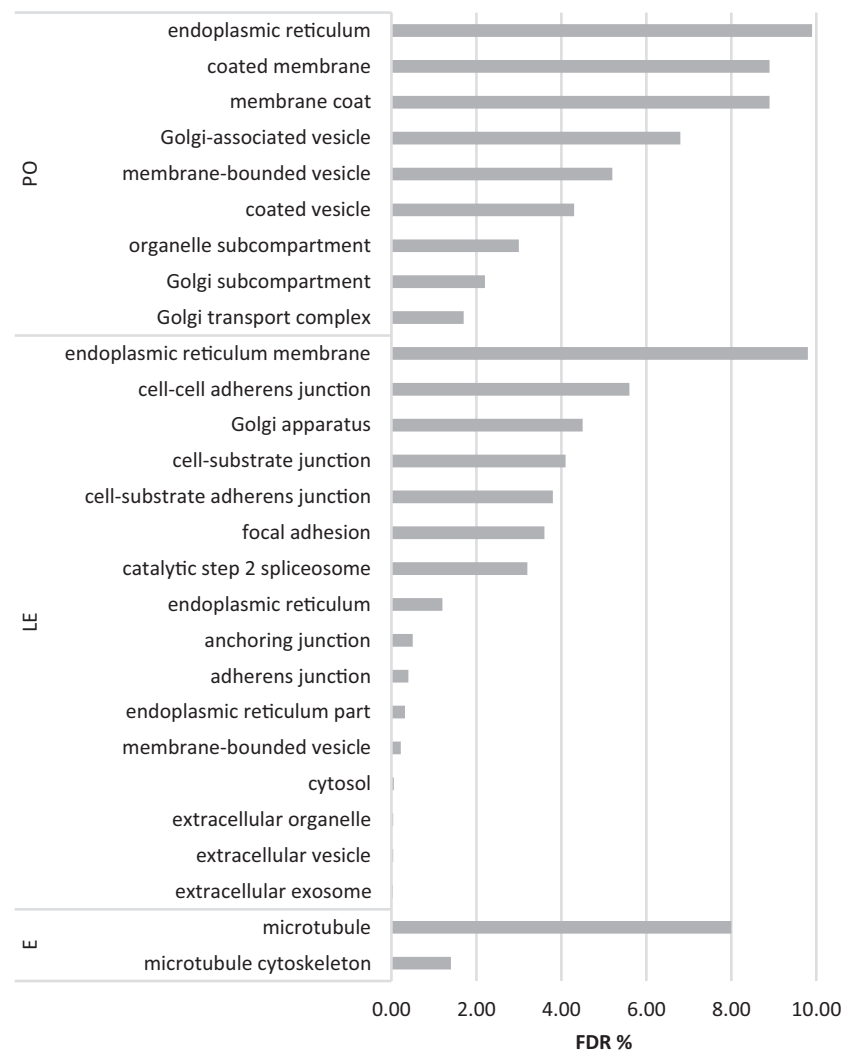

Figure 5 Enriched GO cellular component terms of unique proteins in the E, LE and PO groups, respectively, after analysis by DAVID $(F D R<0.1)$. E, estrus; LE, late estrus; $P O$, post ovulation.

that the population, protein content and protein cargo of EVs dynamically adapted, even within a very narrow timespan. Proteomic analysis showed that estrus (E), late estrus (LE) and post ovulation (PO) samples were clearly separated, indicating that the cycle stages, featured by dramatic hormonal changes around ovulation, exert a profound impact on oviductal EV protein content.

The collection of the oviducts at particular estrus cycle stages was mainly based on the knowledge that sows come quickly into estrus after weaning. As described manifold, sows show the onset of estrus in average $90 \mathrm{~h}$ (4d) after weaning, the ovulation occurs approximately $37 \mathrm{~h}$ (range $35-40 \mathrm{~h}$ ) after the onset of estrus, which is approximately $70 \%$ of the estrus duration of about $53 \mathrm{~h}$ (Kemp \& Soede 1996). Due to the natural occurring variations in the onset of estrus (range 65-145 h) and therefore the time of ovulation after weaning (ovulation time depends on the onset and duration of estrus (Kemp \& Soede 1996, Soede \& Kemp 1997)), it is not solid enough to collect defined oviducts just based on the time after weaning. Therefore, we performed a strict selection process for this study to gain a more precise assessment of the desired estrus cycle stages. For the assignment of the oviducts to the stage groups clinical estimated criteria of the sows before slaughter according to (Soede \& Kemp 1997) were combined with morphological criteria of the ovaries post mortem according to (Carrasco et al. 2008). As proteomic analysis showed that the samples of the different cycle stages were clearly separated, the approach of sample assignment could be considered as confirmed. However, for definite approval or more circumscribed subgroups, endocrine and molecular analysis of animals and tissues would be recommended.

To standardize the EV preparation procedure, all animals with similar age and body weight were selected for the experiment. We adapted the extraPEG method, which has been recently proven superior to the classic differential ultracentrifugation in terms of EV quality and reproducibility; however co-precipitation of low amount non-EV-associated molecules could not be excluded (Rider et al. 2016, Ludwig et al. 2018). Proteomic signatures indicate that EV population was enriched in our preparations, which could be reinforced by the GO cellular components. Besides, neither hemoglobin nor immunoglobulin was detected in the proteomic data, suggesting no or negligible contamination of the OF samples with blood.

CD109 was highly enriched in the EVs from porcine OF in comparison to oviduct tissue. Similarly, Alminana et al. also confirmed high abundance of CD109 in EVs from bovine OF throughout the estrous cycle (Alminana et al. 2018). Moreover, CD109 was only detected in EVs produced in vivo, but absent in EVs derived from primary oviduct epithelial cells in vitro (Alminana et al. 2017), highlighting its specificity. Sakakura et al. also reported CD109 was an exosomal protein in EVs secreted from human HEK293 cells (Sakakura et al. 2016). These suggested CD109 may be a potential marker for EVs originating from OF, probably representing a subtype of EVs or exosomes.

\section{Changes in EV population around the time of ovulation}

Analysis of the EV population unveiled variations in the total number as well as size distribution profile among EVs from different groups. The EV amount as well as the protein concentration of prepared EV samples gradually increased from diestrus (D) to the periovulatory period (E to PO), which is in line with cyclic changes in the volume and protein secretion of OF in pigs (Aguilar \& Reyley 2005, Carrasco et al. 2008). Likewise, in a study analyzing EVs from the ovine uterus lumen the amount of EVs was significantly elevated from day 10 to day 14 during the estrous cycle (Burns et al. 2018). Collectively, these data point toward a regulatory role of steroid hormones on the EV biogenesis pathways in the female reproductive tract. Additionally, the mean size of EVs in E and LE was significantly larger in comparison to PO. This could be explained by a greater proportion of large EVs in the E and LE groups. In support of this, GO 

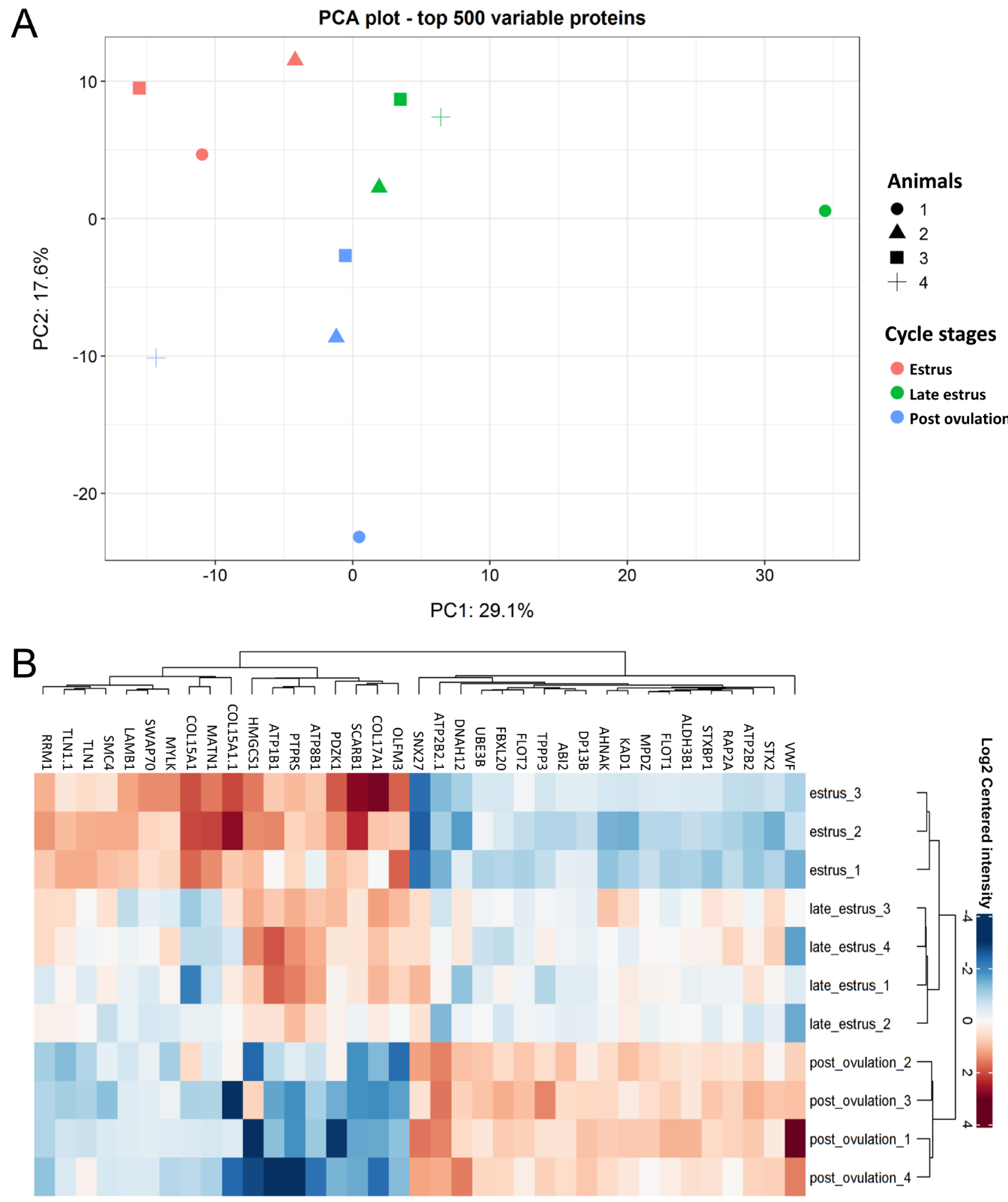

Figure 6 Profile of porcine oviductal EV protein content around the ovulation window. (A) Principal component analysis (PCA) on oviductal EV protein content during estrus, late estrus and post ovulation stages using the top 500 variable proteins (Estrus: red; late estrus: green; post ovulation: blue.) (B) Heat map of the hierarchical clustering of differentially expressed proteins (DEPs, centered log2 intensity) among the E, LE and PO groups. The pairs of ATP2B2 and ATP2B2.1, COL15A1 and COL15A1.1, as well as TLN1 and TLN1.1, are peptides which matched to two different species. 


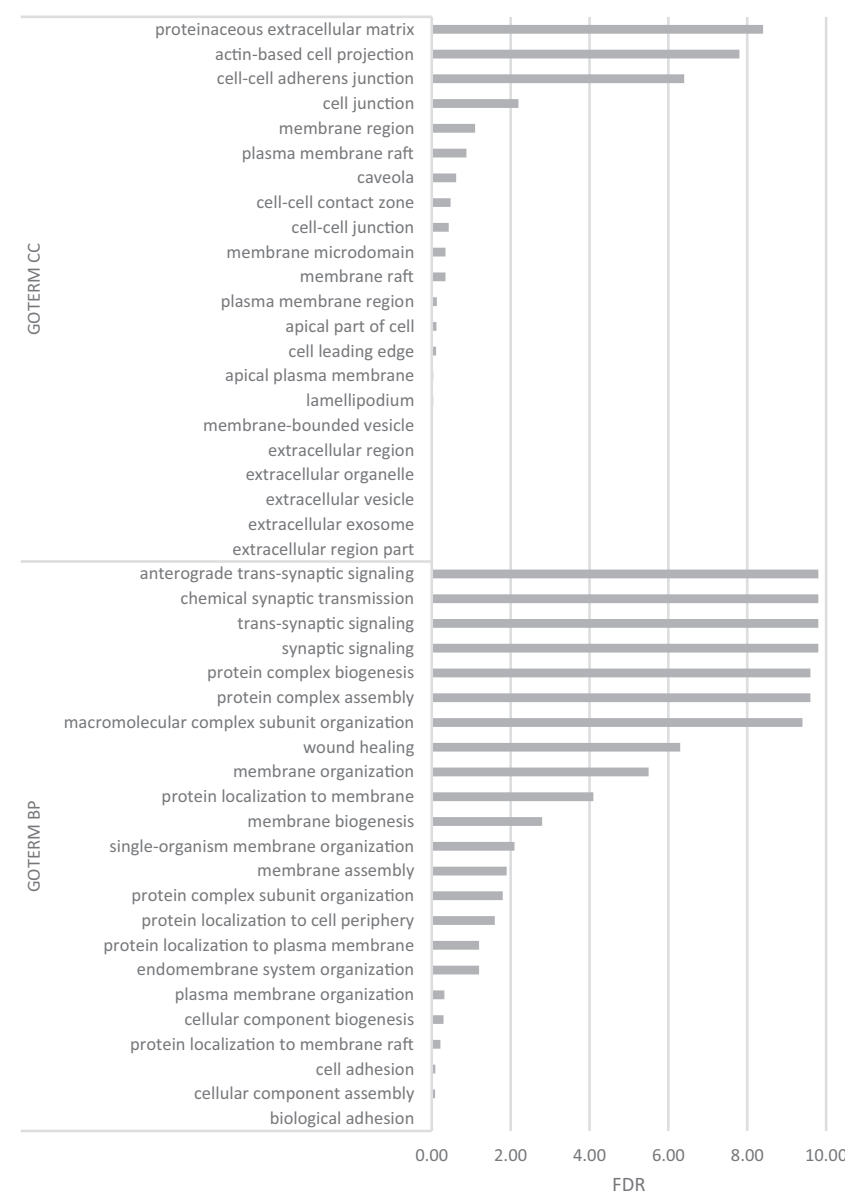

Figure $7 \mathrm{GO}$ cellular component and biological process terms for the DEPs in the comparison between estrus and post ovulation stages. Results were based on the DAVID analysis (FDR $<0.1$ ).

cellular component analysis revealed that proteins in the E group were connected to cytoskeleton microtubules, which are associated with biogenesis of MVs (100 up to $1000 \mathrm{~nm}$ ) (van Niel et al. 2018).

\section{Protein cargo of porcine oviductal EVs}

Despite the fact that the study is based on samples from individual sows which are biologically divergent, global proteomic analysis revealed clear stage-dependent clustering, indicating that the population of EVs and its cargo in the oviductal fluid changes substantially within a few days around the time of ovulation. In view of the dynamic hormonal profile around ovulation, i.e. sequential estrogen and LH peaks in estrus, as well as an initial rise of progesterone after ovulation, it is likely that EV secretion may be under the regulation of steroid hormones. These findings are in consonance with the study on EVs derived from the ovine uterus, as well as the report by Alminana et al., who analyzed EV cargoes from bovine OF across the estrous cycle and discovered marked variation between the pre-ovulatory and post-ovulatory samples (Burns et al. 2014, Alminana et al. 2018). In the bovine study, in total 336 proteins were identified in the oviductal EVs, and $81 \%$ (273 proteins) of them overlapped with the porcine EV protein list. The common abundant proteins include, inter alia, heat shock protein family (HSP90AA1, HSP90B1, HSPA1A, HSPA4, HSPB1, and HSPA8), annexin family (ANXA1, ANXA2, ANXA4, ANXA5, ANXA6, ANXA7, and ANXA11), myosin heavy chain 9 (MYH9), clathrin heavy chain (CLTC), alanyl aminopeptidase membrane (ANPEP), ezrin (EZR), and OVGP1, which are connected to reproductive processes. Notably, we found syntaxin and syntaxin-binding protein (STX2 and STXB1), which involved in fusion of vesicles with plasma membrane, sperm acrosome reaction as well as fertilization, were upregulated during PO stage in comparison to $\mathrm{E}$ stage, which was in agreement with the findings in bovine (Alminana et al. 2018). The ATPase plasma membrane Ca2+ transporting 2 (ATP2B2 or PMCA2), a transport protein which globally controls $\mathrm{Ca} 2+$ efflux, was also found more prominent in PO stage, which however differed from the bovine study. Isoforms of PMCA are essential for the regulation of sperm motility, acrosome reaction, egg activation and embryo development (Yeste et al. 2016, Stafford et al. 2017). The inconsistency in ATP2B2 abundance might hint to a species-specific expression pattern, however, further investigations are needed to validate this.

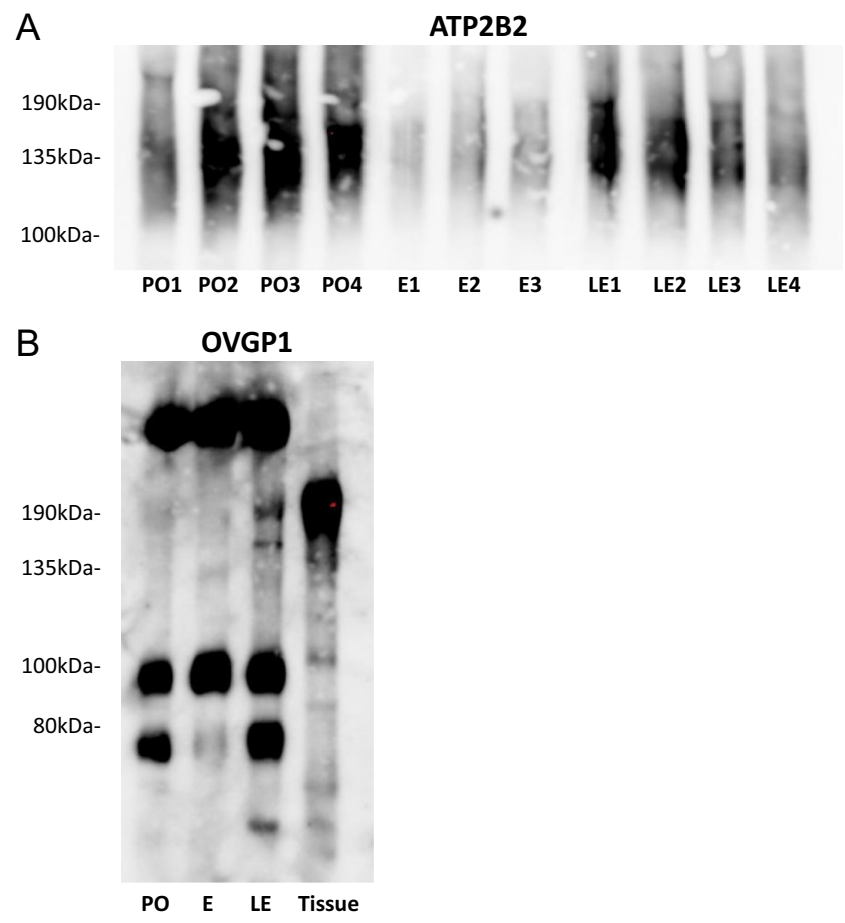

Figure 8 Western blot analysis of ATP2B2 and OVGP1 in oviductal EVs around the time of ovulation. (A) Differential abundance of ATP2B2 in samples during estrus (E), late estrus (LE), and post ovulation stages (PO). (B) The OVGP1 existed in different highly glycosylated forms in porcine oviductal EVs. 
The oviduct specific glycoprotein OVGP1 is known to play a crucial role in sperm-oviduct interaction, fertilization as well as in early embryogenesis (Yang et al. 2012). OVGP1 existed as heavily glycosylated form in the oviductal EVs, suggesting its biological activity. However, whether OVGP1 is loaded into the EVs or just outwardly associated to the vesicle membrane needs still to be elucidated.

Further attention was given to the divergence of proteins among groups. The mRNA expression of all respective DEPs was validated in our recent transcriptomic analysis of porcine oviduct epithelial cells (Chen et al. 2018). The exosome markers Flotillin 1 and 2 (FLOT1 and FLOT2) were more abundant in PO stage, which may explain the highest EV quantity in this group. Among the DEPs between $E$ and PO, a class of ECM proteins was differentially loaded into EVs, including: matrilin 1 (MATN1), laminin subunit beta 1 (LAMB1), collagen type XV alpha 1 chain (COL15A1 or COFA1), and collagen type XVII alpha 1 chain (COL17A1 or COHA1). The ECM components are usually considered as extracellular structural support; however, Kowal et al. have recently illustrated that ECM proteins are associated components to a particular category of small EVs, although the underlying packaging and transport mechanisms remain unclear (Kowal et al. 2016). In support of our findings, Greening et al. also detected regulation of ECM associated proteins in EVs from endometrium in response to hormonal stimulation (Greening et al. 2016).

OLFM3 is known for its role in development and cell differentiation (Anholt 2014). Qualitative and quantitative proteomic analyses both confirmed that this protein gradually decreased from estrus (E) to ovulation (LE) and then to undetectable level after ovulation (PO), suggesting its level may depend on estrogen. Likewise, it has been reported that the expression of talin 1 (TLN1) was suppressed upon exposure to embryonic signals (Shen \& Qin 2019). In our study, we found lowest abundance of TLN1 after ovulation (PO), the stage when the oviduct was exposed to unfertilized oocytes. The 3-hydroxy-3methylglutaryl-CoA synthase 1 (HMGCS1), a major enzyme in cholesterol biosynthesis, scavenger receptor class B member 1 (SCARB1) and PDZ domain-containing 1 (PDZK1), which are involved in cholesterol metabolism, are known to be induced by estrogen and upregulated during the estrous stage in oviduct (Cerny et al. 2015, de Bari et al. 2015, Acuna et al. 2017). In agreement to this, we found higher amount of these proteins in oviductal EVs during estrus (E) than in post ovulation (PO).

In this study we analyzed OF from individual natural cycling sows, meaning that trace amounts of EVs from the follicular fluid or cumulus-oocyte complex may be present, though proteomic analysis detected no obvious evidence. Furthermore, finding significant variances in our ex vivo samples despite of the biological differences among individual animals was surely challenging. Further mechanistic studies using bona fide in vitro models of the oviduct epithelium will therefore deepen our understanding of the role of EVs originating from the oviduct.

In conclusion, this study firstly characterized EVs and their cargoes from the OF around the time of ovulation in pig. We found dynamic EV profiles, in terms of their size, population and protein cargo, suggesting that porcine oviductal EV secretion and protein loading are under hormonal influence of the estrus cycle. The EV protein content was in-depth profiled during the periovulatory period. This data builds the basis for further investigations on the roles of EVs in early embryomaternal communication.

\section{Supplementary materials}

This is linked to the online version of the paper at https://doi. org/10.1530/REP-19-0219.

\section{Declaration of interest}

The authors declare that there is no conflict of interest that could be perceived as prejudicing the impartiality of the research reported.

\section{Funding}

This study is supported by the German Research Foundation (CH2321/1-1; TR 1656/1-1). Inga Laezer was supported by H. - Wilhelm - Schaumann Stiftung, Hamburg, Germany. Authors are active members of the COST Action CA16119 (In vitro 3-D total cell guidance and fitness).

\section{Author contribution statement}

Conceived, designed and supervised the study: S C and J S; Executed the experiments: I L, F L, M F, N T and A V; Analyzed the data: S E P-V, S C, I L, A V and J S; Prepared the table/ figures: S C, I L, S E P-V, A V and N T; Wrote the manuscript: I L and S C; Revised the manuscript: S C and J S; All authors contributed to the final version of the manuscript.

\section{Acknowledgements}

The authors are grateful to Lisa Speck, Bianka Drawert, Gesine Krüger and Silvia Langhoff, FBN Dummerstorf, for their excellent technical support and the workers of the FBN slaughterhouse for providing sample material. They thank Dr Armin Springer and Ute Schulz, Electron Microscopy Centre University of Rostock, Germany, for cooperation and assistance in TEM. They also thank Heike Stephanowitz, Leibniz Institute for Molecular Pharmacology, Berlin, for assistance in proteomic analyses. 


\section{References}

Acuna OS, Aviles M, Lopez-Ubeda R, Guillen-Martinez A, Soriano-Ubeda C, Torrecillas A, Coy P \& Izquierdo-Rico MJ 2017 Differential gene expression in porcine oviduct during the oestrous cycle. Reproduction, Fertility, and Development 29 2387-2399. (https://doi.org/10.1071/RD16457)

Aguilar J \& Reyley M 2005 The uterine tubal fluid: secretion, composition and biological effects. Animal Reproduction 2 91-105.

Al-Dossary AA, Strehler EE \& Martin-Deleon PA 2013 Expression and secretion of plasma membrane Ca2+-ATPase 4a (PMCA4a) during murine estrus: association with oviductal exosomes and uptake in sperm. PLoS ONE 8 e80181. (https://doi.org/10.1371/journal.pone.0080181)

Alminana C, Corbin E, Tsikis G, Alcantara-Neto AS, Labas V, Reynaud K, Galio L, Uzbekov R, Garanina AS, Druart X et al. 2017 Oviduct extracellular vesicles protein content and their role during oviductembryo cross-talk. Reproduction 154 153-168. (https://doi.org/10.1530/ REP-17-0054)

Alminana C, Tsikis G, Labas V, Uzbekov R, da Silveira JC, Bauersachs S \& Mermillod P 2018 Deciphering the oviductal extracellular vesicles content across the estrous cycle: implications for the gametes-oviduct interactions and the environment of the potential embryo. BMC Genomics 19 622. (https://doi.org/10.1186/s12864-018-4982-5)

Anholt RR 2014 Olfactomedin proteins: central players in development and disease. Frontiers in Cell and Developmental Biology 2 6. (https:// doi.org/10.3389/fcell.2014.00006)

Bathala P, Fereshteh Z, Li K, Al-Dossary AA, Galileo DS \& MartinDeLeon PA 2018 Oviductal extracellular vesicles (oviductosomes, OVS) are conserved in humans: murine OVS play a pivotal role in sperm capacitation and fertility. Molecular Human Reproduction 24 143-157. (https://doi.org/10.1093/molehr/gay003)

Brussow KP, Schneider F, Kanitz W, Ratky J, Kauffold J \& Wahner M 2009 Studies on fixed-time ovulation induction in the pig. Society of Reproduction and Fertility Supplement 66 187-195.

Burns G, Brooks K, Wildung M, Navakanitworakul R, Christenson LK \& Spencer TE 2014 Extracellular vesicles in luminal fluid of the ovine uterus. PLOS ONE 9 e90913. (https://doi.org/10.1371/journal. pone.0090913)

Burns GW, Brooks KE, O'Neil EV, Hagen DE, Behura SK \& Spencer TE 2018 Progesterone effects on extracellular vesicles in the sheep uterus. Biology of Reproduction 98 612-622. (https://doi.org/10.1093/biolre/ ioy011)

Carrasco LC, Romar R, Aviles M, Gadea J \& Coy P 2008 Determination of glycosidase activity in porcine oviductal fluid at the different phases of the estrous cycle. Reproduction 136 833-842. (https://doi.org/10.1530/ REP-08-0221)

Cerny KL, Garrett E, Walton AJ, Anderson LH \& Bridges PJ 2015 A transcriptomal analysis of bovine oviductal epithelial cells collected during the follicular phase versus the luteal phase of the estrous cycle. Reproductive Biology and Endocrinology 13 84. (https://doi.org/10.1186/ s12958-015-0077-1)

Chen S, Palma-Vera SE, Langhammer M, Galuska SP, Braun BC, Krause E, Lucas-Hahn A \& Schoen J 2017 An air-liquid interphase approach for modeling the early embryo-maternal contact zone. Scientific Reports 7 42298. (https://doi.org/10.1038/srep42298)

Chen S, Palma-Vera SE, Kempisty B, Rucinski M, Vernunft A \& Schoen J 2018 In vitro mimicking of estrous cycle stages: dissecting the impact of estradiol and progesterone on oviduct epithelium. Endocrinology 159 3421-3432. (https://doi.org/10.1210/en.2018-00567)

Coy P, Garcia-Vazquez FA, Visconti PE \& Aviles M 2012 Roles of the oviduct in mammalian fertilization. Reproduction 144 649-660. (https:// doi.org/10.1530/REP-12-0279)

de Bari O, Wang HH, Portincasa P, Liu M \& Wang DQ 2015 The deletion of the estrogen receptor alpha gene reduces susceptibility to estrogen-induced cholesterol cholelithiasis in female mice. Biochimica and Biophysica Acta 1852 2161-2169. (https://doi.org/10.1016/j. bbadis.2015.07.020)

Edgar JR 2016 Q\&A: what are exosomes, exactly? BMC Biology 1446. (https://doi.org/10.1186/s12915-016-0268-z)

Georgiou AS, Sostaric E, Wong CH, Snijders AP, Wright PC, Moore HD \& Fazeli A 2005 Gametes alter the oviductal secretory proteome. Molecular and Cellular Proteomics 4 1785-1796. (https://doi.org/10.1074/mcp. M500119-MCP200)
Greening DW, Nguyen HP, Elgass K, Simpson RJ \& Salamonsen LA 2016 Human endometrial exosomes contain hormone-specific cargo modulating trophoblast adhesive capacity: insights into endometrialembryo interactions. Biology of Reproduction 94 38. (https://doi. org/10.1095/biolreprod.115.134890)

Harding C, Heuser J \& Stahl P 1983 Receptor-mediated endocytosis of transferrin and recycling of the transferrin receptor in rat reticulocytes. Journal of Cell Biology 97 329-339. (https://doi.org/10.1083/ jcb.97.2.329)

Henricks DM, Guthrie HD \& Handlin DL 1972 Plasma estrogen, progesterone and luteinizing hormone levels during the estrous cycle in pigs. Biology of Reproduction 6 210-218. (https://doi.org/10.1093/ biolreprod/6.2.210)

Huang da W, Sherman BT \& Lempicki RA 2009 Systematic and integrative analysis of large gene lists using David bioinformatics resources. Nature Protocols 4 44-57. (https://doi.org/10.1038/nprot.2008.211)

Huber W, von Heydebreck A, Sultmann H, Poustka A \& Vingron M 2002 Variance stabilization applied to microarray data calibration and to the quantification of differential expression. Bioinformatics 18 (Supplement 1) S96-S104. (https://doi.org/10.1093/bioinformatics/18.suppl_1.s96)

Huber W, Carey VJ, Gentleman R, Anders S, Carlson M, Carvalho BS, Bravo HC, Davis S, Gatto L, Girke T et al. 2015 Orchestrating highthroughput genomic analysis with Bioconductor. Nature Methods 12 115-121. (https://doi.org/10.1038/nmeth.3252)

Hughes CS, Moggridge S, Muller T, Sorensen PH, Morin GB \& Krijgsveld J 2019 Single-pot, solid-phase-enhanced sample preparation for proteomics experiments. Nature Protocols 14 68-85. (https://doi. org/10.1038/s41596-018-0082-x)

Kemp B \& Soede NM 1996 Relationship of weaning-to-estrus interval to timing of ovulation and fertilization in sows. Journal of Animal Science 74 944-949. (https://doi.org/10.2527/1996.745944x)

Kowal J, Arras G, Colombo M, Jouve M, Morath JP, Primdal-Bengtson B, Dingli F, Loew D, Tkach M \& Thery C 2016 Proteomic comparison defines novel markers to characterize heterogeneous populations of extracellular vesicle subtypes. PNAS 113 E968-E977. (https://doi. org/10.1073/pnas.1521230113)

Lamy J, Labas V, Harichaux G, Tsikis G, Mermillod P \& Saint-Dizier M 2016 a Regulation of the bovine oviductal fluid proteome. Reproduction 152 629-644. (https://doi.org/10.1530/REP-16-0397)

Lamy J, Liere P, Pianos A, Aprahamian F, Mermillod P \& Saint-Dizier M $2016 b$ Steroid hormones in bovine oviductal fluid during the estrous cycle. Theriogenology 86 1409-1420. (https://doi.org/10.1016/j. theriogenology.2016.04.086)

Lamy J, Gatien J, Dubuisson F, Nadal-Desbarats L, Salvetti P, Mermillod P \& Saint-Dizier M 2018 Metabolomic profiling of bovine oviductal fluid across the oestrous cycle using proton nuclear magnetic resonance spectroscopy. Reproduction, Fertility, and Development 30 1021-1028. (https://doi.org/10.1071/RD17389)

Lee Y, El S \& Wood MJ 2012 Exosomes and microvesicles: extracellular vesicles for genetic information transfer and gene therapy. Human Molecular Genetics 21 R125-R134. (https://doi.org/10.1093/hmg/ dds317)

Leese HJ 1988 The formation and function of oviduct fluid. Journal of Reproduction and Fertility 82 843-856. (https://doi.org/10.1530/ jrf.0.0820843)

Li S \& Winuthayanon W 2017 Oviduct: roles in fertilization and early embryo development. Journal of Endocrinology 232 R1-R26. (https:// doi.org/10.1530/JOE-16-0302)

Lopera-Vasquez R, Hamdi M, Fernandez-Fuertes B, Maillo V, BeltranBrena P, Calle A, Redruello A, Lopez-Martin S, Gutierrez-Adan A, Yanez-Mo M et al. 2016 Extracellular vesicles from BOEC in in vitro embryo development and quality. PLOS ONE 11 e0148083. (https://doi. org/10.1371/journal.pone.0148083)

Lopera-Vasquez R, Hamdi M, Maillo V, Gutierrez-Adan A, BermejoAlvarez P, Ramirez MÁ, Yanez-Mo M \& Rizos D 2017 Effect of bovine oviductal extracellular vesicles on embryo development and quality in vitro. Reproduction 153 461-470. (https://doi.org/10.1530/REP-160384)

Ludwig AK, De Miroschedji K, Doeppner TR, Borger V, Ruesing J, Rebmann V, Durst S, Jansen S, Bremer M, Behrmann E et al. 2018 Precipitation with polyethylene glycol followed by washing and pelleting by ultracentrifugation enriches extracellular vesicles from tissue culture 
supernatants in small and large scales. Journal of Extracellular Vesicles 7 1528109. (https://doi.org/10.1080/20013078.2018.1528109)

Maillo V, Sanchez-Calabuig MJ, Lopera-Vasquez R, Hamdi M, GutierrezAdan A, Lonergan P \& Rizos D 2016 Oviductal response to gametes and early embryos in mammals. Reproduction 152 R127-R141. (https://doi. org/10.1530/REP-16-0120)

Pavani KC, Alminana C, Wydooghe E, Catteeuw M, Ramirez MA, Mermillod P, Rizos D \& Van Soom A 2016 Emerging role of extracellular vesicles in communication of preimplantation embryos in vitro. Reproduction, Fertility, and Development 29 66-83. (https://doi. org/10.1071/RD16318)

Rider MA, Hurwitz SN \& Meckes DG Jr 2016 ExtraPEG: a polyethylene glycol-based method for enrichment of extracellular vesicles. Scientific Reports 6 23978. (https://doi.org/10.1038/srep23978)

Ritchie ME, Phipson B, Wu D, Hu Y, Law CW, Shi W \& Smyth GK 2015 Limma powers differential expression analyses for RNA-sequencing and microarray studies. Nucleic Acids Research 43 e47. (https://doi. org/10.1093/nar/gkv007)

Sakakura H, Mii S, Hagiwara S, Kato T, Yamamoto N, Hibi H, Takahashi M \& Murakumo Y 2016 CD109 is a component of exosome secreted from cultured cells. Biochemical and Biophysical Research Communications 469 816-822. (https://doi.org/10.1016/j.bbrc.2015.12.063)

Shen Y \& Qin A 2019 Regulation of embryonic signal on Talin1 in mouse endometrium. Reproductive Sciences 26 1277-1286. (https://doi. org/10.1177/1933719118815584)

Soede NM \& Kemp B 1997 Expression of oestrus and timing of ovulation in pigs. Journal of Reproduction and Fertility 52 91-103.

Soleilhavoup C, Riou C, Tsikis G, Labas V, Harichaux G, Kohnke P, Reynaud K, de Graaf SP, Gerard N \& Druart X 2016 Proteomes of the female genital tract during the oestrous cycle. Molecular and Cellular Proteomics 15 93-108. (https://doi.org/10.1074/mcp.M115.052332)

Stafford N, Wilson C, Oceandy D, Neyses L \& Cartwright EJ 2017 The Plasma Membrane Calcium ATPases and Their Role as Major New Players in Human Disease. Physiological Reviews 97 1089-1125. (https:// doi.org/10.1152/physrev.00028.2016)

Thery C, Amigorena S, Raposo G \& Clayton A 2006 Isolation and characterization of exosomes from cell culture supernatants and biological fluids. Current Protocols in Cell Biology Chapter 3 Unit 3.22. (https://doi.org/10.1002/0471143030.cb0322s30)

Thery C, Witwer KW, Aikawa E, Alcaraz MJ, Anderson JD, Andriantsitohaina R, Antoniou A, Arab T, Archer F, Atkin-Smith GK et al. 2018 Minimal information for studies of extracellular vesicles 2018 (MISEV2018): a position statement of the international society for extracellular vesicles and update of the MISEV2014 guidelines. Journal of Extracellular Vesicles 7 1535750. (https://doi.org/10.1080/20013078. 2018.1535750)

van Niel G, D'Angelo G \& Raposo G 2018 Shedding light on the cell biology of extracellular vesicles. Nature Reviews: Molecular Cell Biology 19 213-228. (https://doi.org/10.1038/nrm.2017.125)

Wickham H 2007 Reshaping data with the reshape package. Journal of Statistical Software 21 1-20. (https://doi.org/10.18637/jss.v021.i12)

Wickham H 2009 Ggplot2: Elegant Graphics for Data Analysis. SpringerVerlag: New York.

Yang X, Tao S, Orlando R, Brockhausen I \& Kan FW 2012 Structures and biosynthesis of the $\mathrm{N}$ - and O-glycans of recombinant human oviduct-specific glycoprotein expressed in human embryonic kidney cells. Carbohydrate Research 358 47-55. (https://doi.org/10.1016/j. carres.2012.05.027)

Yeste M, Jones C, Amdani SN, Patel S \& Coward K 2016 Oocyte activation deficiency: a role for an oocyte contribution? Human Reproduction Update 22 23-47. (https://doi.org/10.1093/humupd/dmv040)

Zhang X, Smits AH, van Tilburg GB, Ovaa H, Huber W \& Vermeulen M 2018 Proteome-wide identification of ubiquitin interactions using UblA-MS. Nature Protocols 13 530-550. (https://doi.org/10.1038/ nprot.2017.147)

Received 17 May 2019

First decision 27 June 2019

Revised manuscript received 6 January 2020

Accepted 16 January 2020 